\title{
On Vocabulary Presentation Modes in College English Teaching and Learning
}

\author{
Jun Chen \\ School of Foreign Languages, Huaiyin Institute of Technology, Huaian, China
}

\begin{abstract}
Vocabulary is one of the most indispensable components in a language. The most important way teachers use to teach new vocabularies is vocabulary presentation mode, and how the new vocabularies are presented in English teaching and learning will have a great influence on the students' EFL vocabulary retention. This paper mainly elaborates the researches on some effective vocabulary presentation modes abroad and at home in order to help college students master vocabulary presentation modes so that they can learn the new vocabularies efficiently, and improve English vocabulary teaching and learning level.
\end{abstract}

Index Terms - vocabulary, vocabulary presentation modes, English vocabulary teaching and learning

\section{INTRODUCTION}

As is widely known, vocabulary is essential to a language. It is one of the three basic components-pronunciation, vocabulary and grammar, and is very important to people's communication and language learning. Just as the famous linguist David Wilkins once put that without grammar little can be conveyed, without vocabulary nothing can be conveyed (Wilkins, 1972). And language researchers and teachers have already recognized the importance of vocabulary and vocabulary teaching. According to Lawson \& Hogben (1996) and Nation (1993, 2001), vocabulary acquisition, important as it is, has received scant attention in the international research agenda. However, Coady (1993) and Rott (1999) put that research done in the skill areas asserts that effective communication is a function of adequate and appropriate vocabulary acquisition rather than the learning of grammar rules. As is widely accepted, vocabulary is "of critical importance to the typical language learner" (Zimmerman, 2001, p. 5).

The important role of acquiring vocabularies in foreign language learning has been increasingly recognized and emphasized in college English teaching and learning in China. According to College English Curriculum Requirement (2007) issued by Ministry of Education of The People's Republic of China, "The requirements for undergraduate College English teaching are set at three levels, i.e., basic requirements, intermediate requirements, and higher requirements. The basic requirements are the minimum level that all non-English majors have to reach before graduation. Recommended Vocabulary: Students should acquire a total of 4,795 words and 700 phrases (including those that are covered in high school English courses), among which 2,000 are active words. Students should not only be able to comprehend the active words but be proficient in using them when expressing themselves in speaking or writing." (Ministry of Education, 2007, p. 2-4).

Therefore, this is why more and more language learners, practitioners(instructors) and researchers are considering vocabulary as being a vitally important, if not the most important, element in language learning (Nation, 1990), and vocabulary instruction has been playing a significant role in the English language teaching and learning. Zhang Baicheng (2004) argues that in the process of vocabulary instruction, showing or introducing target words or lexical items to learners is called vocabulary presentation which is very important, and using appropriate presentation methods enables learners to obtain a deeper impression of and richer information about the target words to make them enter the long-term memory more easily. This study is going to review some theories about vocabulary presentation modes abroad and at home, which will be helpful for students to memorize vocabularies and have good retention of them.

\section{Vocabulary Presentation Modes}

In this part, some literature related to vocabulary presentation modes will be reviewed, which contains some researches on vocabulary presentation modes abroad and at home.

\section{A. Presentation}

According to the Oxford Dictionary of English (online), "presentation is the manner or style in which something is given, offered, or displayed." And "presentation, the first stage in language teaching, is defined as "the introduction of new items, when their meanings are explained, demonstrated, etc., and other necessary information is given" (Longman Dictionary of Language Teaching \& Applied Linguistics, 2002). According to the definitions above, presentation is the first stage in language teaching, during which new language items, meanings and necessary information are introduced. Therefore, in English vocabulary teaching, vocabulary presentation is the procedure during which appropriate modes or strategies will be used to introduce new vocabularies to the learners (students). According to Cross (1991) and Nation 
(1990), presentation strategies are those that introduce the target vocabulary for the first time. These will involve either presentation of the meaning (i.e. concept) or the form. Cross (1991) put that among the meaning strategies are visual strategies like the use of pictures, body actions, real objects or video, verbal presentation strategies like definition, translation, or exemplification and audio strategies like imitation of sound or having learners listen to a tape-recording , introducing the target vocabulary items (words) to learners.

\section{B. Researches on Vocabulary Presentation Modes Abroad}

\section{Visual Techniques, Verbal Techniques and Dictionaries}

How should new words be presented in classroom vocabulary teaching? Different researchers have different answers to this question. Gairns \&Redman (1986) argue that traditional approaches and techniques used in the presentation of new vocabulary items can be divided into three categories, namely visual techniques, verbal techniques and dictionaries According to their statement, visual techniques include flashcards, photographs, blackboard drawings, wallcharts, mime, gesture, etc.. Visual techniques for the presentation of new lexical items pertain to visual memory, which is considered helpful especially with vocabulary retention. Learners can remember the presented material far more effectively if it has been presented by means of visual aids. They help students associate presented material in a meaningful way and incorporate it into their existing system of language; Verbal techniques include use of illustrative situations, use of synonymy and definition, contrasts and opposites, scales, and examples of the type.

\section{10 Ways of Presenting the Meaning of New Vocabulary Items}

Penny Ur (2000) offered 10 ways of presenting the meaning of new vocabulary items: 1) concise definition; 2) detailed description; 3) examples (hyponyms); 4) illustration (picture, object); 5) demonstration (acting, mime); 6) context (story or sentence in which the item occurs); 7) synonyms; 8) opposites (antonyms); 9) translation; 10) associated ideas, collocations. And these ways are often used to present new vocabularies to learners by teachers in the process of vocabulary teaching.

\section{Presenting Words in Context}

To be specific, some researchers did studies on the importance of some vocabulary presentation modes in vocabulary teaching. Fischer (1994) compared some ways of word presentation and concluded that the way of presenting words in context is more effective than that in non-context. "The importance of context in vocabulary presentation and learning is stated as follows: what a word means on any given occasion is mediated by the many contexts in which it is used, and such contexts provide considerable input from which language users clearly pick up huge amounts of vocabulary knowledge, apart from any explicit vocabulary instruction they may receive" (William Nagy, 2002, p.64). Guessing word meaning in context is also important, which involves generalizable skills of interpreting surrounding text, predicting, and testing predictions while reading, which enhance reading skills as a whole (Coady \& Nation, 1988).

\section{Lexical Chunks}

Nattinger (1992) defined lexical chunks as multi-word chunks of language of varying length that run on a continuum from fixed phrases. And he also pointed out that such phrases will likewise enable students not to violate certain lexical restrictions, nor produce as many incongruities of register.

The above studies on the modes of vocabulary presentation are about the ways or strategies of presenting new words to the learners in vocabulary teaching and learning, and about the importance of some specific vocabulary presentation modes in presenting new words to the learners.

\section{Researches on Vocabulary Presentation Modes at Home}

\section{Word Strategy, Collocation Strategy and Association Strategy}

Some researchers put forward several strategies of vocabulary presentation in vocabulary teaching. Leng Jie \& Su Xiaojun (2009) discussed the basic principles and content of vocabulary presentation, and suggested that teachers should adopt the word frequency strategy, appropriate word strategy, collocation strategy and association strategy.

\section{Empirical Researches on Modes of Contextual Presentation and Lexical Presentation}

Besides, some empirical researches on modes of contextual presentation and lexical presentation were conducted to test which of the two modes is better in presenting new words to the students in vocabulary teaching. Researchers like He Jianing (1998), Wang Zongyan (2001), Lu Qiaoling (2001), Zhang Ruihua \& Chen Jiansheng (2003) and Wei Yanli (2007), they all did researches on the mode of contextual presentation, and found that contextual presentation is a better way of presenting new words to students and the students can master the new words by using certain knowledge of context and its clues. Wei Yanli (2007) and Zhang Ruihua \& Chen Jiansheng (2003) also pointed out that contextual presentation is a better way to present new vocabularies to students than lexical presentation. Singer said, "in a reading activity, understanding vocabulary is about 39\% of a reader's reading competence, and a reader's ability to understand vocabulary in texts $47 \%$ relies on his or her vocabulary size, and $28 \%$ of the reading speed is used to recognize vocabulary." (as cited in Sun Xingwen, 1998, p. 101).

\section{Wordlist and Semantic Field}

Wordlist and semantic field play an important role in presenting new words to the learners in vocabulary teaching. He Jianing (1998) pointed out that if students want to memorize more words within a relatively short period of time, the ways of presenting words by using wordlist and semantic field will help. Zeng Jianxiang (2007) concluded that thematic clustering mode of presentation is more effective than semantic clustering mode by doing an experiment on how three 
different modes of word presentation influence intermediate-level EFL learners' learning of English words. Zhang Li \& Sheng Yue's study (2009) also revealed that words in semantically unrelated sets will be more helpful for memory than those in semantically related sets.

\section{Presenting Words by Stimulating Guesses}

As for the vocabulary presentation mode of presenting words by stimulating guesses, Wang Ying (2006) made some suggestions for guessing word's meaning from context: learners should grasp the basic vocabulary quickly in order to infer word meaning effectively, and master correct ways for the purpose of making fewer mistakes in guessing word's meaning. Wang Xudong (2009) put forward seven strategies of learning vocabularies in context, they are using context clues directly, synonym clues, antonym clues, word association clues, repeated context, comparison context clues and affix clues.

\section{Lexical Chunks}

"Lexical chunks are the ideal memory model, which can increase the number of words one time and help students keep these words longer in their memory in vocabulary teaching and learning." (Wu Jing \& Wang Ruidong, 2002, p. 66-70; Liu Xiaoling \& Yang Zhiqing, 2003, p.51-55; Pu Jianzhong, 2003, p. 438-446). Both Yu Xiulian's (2008) and Gai Shuhua's (2010) empirical researches further stressed the effects of lexical chunks, that is, lexical chunks could help students with their improvement in English proficiency. And Pu Jianzhong (2003) even offered some suggestions about how to teach lexical chunks: new vocabularies should be put or presented in context and students should take key context (chunks embodying the typical colligations and collocations) into their consideration when learning these new vocabularies.

\section{Vocabulary PResentation Modes In College in China}

\section{A. The Current Situation of Vocabulary Presentation in College in China}

Vocabulary presentation is playing a fundamentally significant and active role in English vocabulary teaching and learning in China. Researchers and teachers are attaching great importance to it, and there are an increasing number of studies on it at home and abroad. Nevertheless, the author of the paper finds that the above studies about the modes of vocabulary presentation mainly focus on the strategies of using them in vocabulary teaching and learning, the importance and influence of some vocabulary presentation modes have on children's and English beginners' vocabulary learning and retention. There are few researchers doing researches on vocabulary presentation modes in college English teaching and learning in China, they are as follows:

In 2000, He Yin put forward that there are two problems in college English vocabulary teaching at present. One is called "inherent problems", namely, there is no coherence in English learning between and among college, middle school and primary school. Another is "lack of proper care after birth", that is to say, methods used in college English vocabulary teaching are not suitable for college students, the English learning to attend. He held that vocabulary teaching should be instructed in order to expand students' vocabulary, so as to improve English learning efficiency. And he also proved that direct or explicit teaching of vocabulary is better for students to learn vocabulary than indirect or implicit teaching of vocabulary by conducting the experiment. Chai Hui and Zhang Zhen (2005) did an experiment of impact of concentrating on teaching vocabulary on students' vocabulary, and the results show that the method to concentrate on teaching English vocabulary makes college students' vocabulary get improvement and expands students' vocabulary and enhance college students' English competence in listening, speaking, reading and writing, and eventually improves college English teaching quality. Zhang Fangying (2006) pointed out, in her essay Analysis of Investigation of College Non-english Majors' vocabulary Learning Method, that it is necessary to teach and learn vocabularies directly. Direct learning can help learners to quickly establish a certain amount of vocabulary for reading, and will help learners associate new words they encountered with words in their brain. Repeatedly, the learners eventually master the meaning and use of vocabulary.

\section{B. The Two Vocabulary Teaching or Presenting Approaches in College in China}

The above researches on vocabulary presentation modes are concerned with the vocabulary presentation mode of wordlist and the vocabulary presentation mode of context. This paper is going to elaborate some vocabulary presentation modes in order to help college students master vocabulary presentation modes so that they can learn the new vocabularies efficiently, and improve English vocabulary teaching and learning level as well.

According to the characteristics of nature of language and the characteristics of foreign language teaching, Shu Dingfang \& Zhuang Zhixiang (2004) pointed out that any form of foreign language teaching should follow these several principles: 1) system principle; 2) communicative principle; 3) culture principle; 4) cognitive principle; 5) emotional principle. On the basis of these principles, the foreign language vocabulary teaching or presenting approaches can be divided into two categories according to different teaching purposes and characteristics: one is called "direct or explicit teaching (presentation) of vocabulary", another is "indirect or implicit teaching (presentation) of vocabulary".

\section{Direct or Explicit Teaching (Presentation) of Vocabulary}

The so-called "direct or explicit teaching (presentation) of vocabulary" means that vocabulary teaching or presenting is considered as a part of teaching goal, carrying on analysis, explanation and drill of the structure of the word (including its pronunciation, meaning and usage). As discussed above, there are several vocabulary presentation modes, 
which are actually and essentially important in English vocabulary teaching and learning. Therefore, it is necessary to summarize some widely used vocabulary presentation modes for college English vocabulary teaching and learning according to direct or explicit teaching (presentation) of vocabulary. And direct or explicit teaching (presentation) of vocabulary includes wordlist, semantic field, lexical chunks, visual techniques, association, verbal techniques and dictionaries. Students are familiar with these methods of teaching (presentation) of vocabulary, because it is easy to be accepted by the students if these methods of teaching (presentation) of vocabulary in college English vocabulary teaching and learning. The aim of using wordlist, semantic field, lexical chunks, visual techniques, verbal techniques and dictionaries to present new words to the students is clear and easy to be completed. The biggest drawback of these direct or explicit vocabulary presentation modes is tedious in the process of English vocabulary teaching and learning. For this reason, these direct or explicit vocabulary presentation modes are suitable for beginners and intermediate learners at college.

\section{Indirect or Implicit Teaching (Presentation) of Vocabulary}

The so-called "indirect or implicit vocabulary teaching (presentation)" is an approach which can help learners achieve the goal of expanding their vocabulary indirectly by participating in learning activities, such as reading and listening. In foreign language teaching, requirements of vocabulary for learners in various stages of foreign language learning are not the same. According to College English Curriculum Requirement (2007), "The requirements for undergraduate College English teaching are set at three levels. The basic requirements are the minimum level that all non-English majors have to reach before graduation. Recommended Vocabulary: Students should acquire a total of 4,795 words and 700 phrases (including those that are covered in high school English courses), among which 2,000 are active words. Students should not only be able to comprehend the active words but be proficient in using them when expressing themselves in speaking or writing." (Ministry of Education, 2007, p. 2-4).

Therefore, it is also essential to do some researches on vocabulary teaching (presentation) for advanced learners at college. The so-called indirect or implicit vocabulary teaching (presentation) here mainly means teaching or presenting the students new words in context. "What really makes learners obtain ability to accurately understand and use words is teaching or presenting the learners new words in communication, namely, by using indirect or implicit vocabulary teaching (presentation) approach."(Yu Caixia, 2009, p.5). "Studies show that with the gradual improvement of learners' foreign language level, the learners will need the method 'reasoning' or 'indirect or implicit vocabulary teaching (here refers to presenting new words in context)' in their vocabulary learning." (Li Hongmei, 2001, p.5). In 1923, Malinowski put forward the concept of context. In 1964, Halliday came up with the concept of register, which means language environment. Hymes defined context as form and context of text, setting, participants and needs and so on. Mondria and Wit-de Boer (1991) pointed out that inferring meaning of a word from its context relates to the retention of that word. In 1996, Prince considered that contextualization helps the learners to figure out, retain and use words. Cheng Anmei (2002) put emphasis on teaching vocabulary in context. Huang Wei (2006) held discussion on the application of lexical and grammatical contexts to the teaching of words. Liang Ming (2006) put that teaching vocabulary in context could improve students' vocabulary retention. According to the theory of memory, comprehensible input can have a lasting memory. So when the learners' English level reaches a certain stage, vocabulary teaching or presentation should be linked to the context. Context includes the article itself or conversation occurred in this article, and all kinds of social environment. Word will be meaningless without some contexts. From this point of view, the contest is very important. Teachers in college should present words in a certain context for the students to learn. A word should be endowed with life in a context. It is also the context that help the students remember words more easily and understand their usage. In a word, contextual teaching or presenting can help the students to understand the usage and various meanings of words more profoundly. Using the context to help learners understand the denotative meaning and connotative meaning of vocabularies. The students will not forget the meaning and usage of a word. An example will be given to illustrate how a word is presented in context by citing a short paragraph from an article called Time-Conscious Americans in NEW HORIZON COLLEGE ENGLISH (Book2, Second Edition, 2008) published by Foreign Language Teaching and Research Press.

"A foreigner's first impression of the US is likely to be that everyone is in a rush —often under pressure. City people always appear to be hurrying to get where they are going, restlessly seeking attention in a store, and elbowing others as they try to complete their shopping. Racing through daytime meals is part of the pace of life in this country. Working time is considered precious. Others in public eating places are waiting for you to finish so that they, too, can be served and get back to work within the time allowed. You also find drivers will be abrupt and people will push past you. You will miss smiles, brief conversations, and small exchanges with strangers. Don't take it personally. This is because people value time highly, and they resent someone else "wasting" it beyond a certain appropriate point." (Zheng Shutang, 2008, p. 3).

The above short paragraph is designed to present the new word "restlessly". The students will be able to guess the meaning of the word "restlessly" in context. Because the title Time-Conscious Americans and the short paragraph all center on the topic of how Americans treat their time as if it were something almost real. From the context, the students can also know the meanings of collocations or short sentences like in a rush, be hurrying to and elbowing others as they try to complete their shopping, so the students can guess the meaning of the word "restlessly"- unable to keep still because one is nervous, bored, or impatient. Through this way, the students can not only master the meaning and usage 
of this word but also cultivate their thinking ability.

\section{CONCLUSION}

Vocabulary presentation is playing a fundamentally important part in English vocabulary teaching and learning in college in China. Researchers and teachers are taking great interest in it. Therefore, teachers and students are supposed to study vocabulary presentation modes and make good use of these vocabulary presentation modes in teaching and learning new words. In the meantime, more empirical researches on vocabulary presentation modes are encouraged in China in the future to further test whether these vocabulary presentation modes are effective or not in helping the students' vocabulary retention.

\section{REFERENCES}

[1] Coady, J. (1993). Research on ESL/EFL vocabulary acquisition: Putting it in context. In T. Huckin, M. Haynes, \& J. Coady (Eds.), Second language reading and vocabulary learning (pp. 3-23). Norwood, NJ: Ablex.

[2] Cross, D. (1991). A Practical Handbook of Language Teaching. London: Longman.

[3] Fischer,U. (1994). Learning words from context and dictionaries: An experimental comparison. Applied Psycholinguistics, 15, 551-574.

[4] Gairns,Redman. (1986). Working with Words: A guide to teaching and learning vocabulary, Cambridge: Cambridge University Press.

[5] He Jianing. (1998). Empirical researches on effecs of vocabulary presentation modes on vocabulary retention. Shandong Foreign Language Teaching Journal, 2,60-63.

[6] Lawson, M. J., \& Hogben, D. (1996). The vocabulary learning strategies of foreign-language students. Language Learning, 46,101-135.

[7] Leng Jie \& Su Xiaojun. (2009). Strategies of preseniting words in English vocabulary teaching. Journal of Suzhou University, 6, 93-95.

[8] Liu Xiaoling \& Yang Zhiqing. (2003). Lexical chunk instruction —a new approach to second language teaching. Foreign Language Education, 6,51-55.

[9] Ministry of Education. (2007). College English Curriculum Requirement, Shanghai, CHINA: Shanghai Foreign Language Education Press.

[10] Mondria,J.\& M.Wit-de Boer. (1991). The Effects of Contextual Richness on the Guessability and the Retention fo Words in a Foreign Language . Applied Linguistics, 12,249-267.

[11] Nation, I. S. P. (1993). Vocabulary size, growth, and use. In R. Schreuder \& B. Weltens (Eds.), The bilingual lexicon (p. 115-124). Amsterdam/Philadelphia: John Benjamins.

[12] Nation, I. S. P. (2001). Learning vocabulary in another language. Cambridge: Cambridge University Press.

[13] Nation, I. S. P. (1990). Teaching and learning vocabulary, New York: Newbury House Publishers.

[14] Oxford Dictionaries. http://www.oxforddictionaries.com/definition/english/presentation?q=presentation (accessed 10/2/2014).

[15] Penny Ur. (2000). A course in Language Teaching: Practice and Theory. Beijing, CHINA: Foreign Language Teaching and Research Press.

[16] Richards, J. C, Platt, J., \& Platt, H. (2002). Longman dictionary of language teaching \& applied linguistics, Beijing, CHINA: Foreign Language Teaching and Study Press.

[17] Rott, S. (1999). The effect of exposure frequency on intermediate language learners' incidental vocabulary acquisition and retention through reading. Studies in Second Language Acquisition, 21, 589-619.

[18] Shu Dingfang\&Zhuang Zhixiang.(2004). Modern Foreign Language Teaching. Shanghai, CHINA: Shanghai Foreign Language Education Press.

[19] Sun Xingwen.(1998). Reflections on the current English vocabulary instruction in colleges and universities. Journal of Sichuan Teachers College (Philosophy and Social Sciences) ,2, 101-106.

[20] Wang Ying. (2006). Improving efficiency of guessing word meaning and acquisition in context. Jiangsu Foreign Language Teaching and Research, 2,47-50.

[21] Wang Zongyan. (2001). An exploratory study of English vocabulary teaching. Journal of PLA University of Foreign Languages, 5, 1-3.

[22] Wilkins, D. A. (1972). Linguistics in Language Teaching. London: Edward Arnold.

[23] William Nagy. (2002). On the role context in first- and second-language vocabulary learning. In N. Schmitt\& M. McCarthy (Eds.), Vocabulary: Description, Acquisition and Pedagogy (p64). Shanghai: Shanghai Foreign Language Education Press.

[24] Wu Jing \& Wang Ruidong.(2002). Lexical chunks - the potential resources for English learning and teaching. Shandong Foreign Language Teaching Journal, 3,66-70.

[25] Yu Xiulian.(2008). An experimental study on lexical approach and practical English competence. Foreign Language World, 3 , 54-61.

[26] Zhang, Baicheng. (2004). Elaboration theory and English vocabulary teaching and learning. Teaching Research, 4, 349-352.

[27] Zhang Li \& Sheng Yue. (2009). A study of the influence of semantically-relatedness of word-sets on L2 Vocabulary Acquisition. Foreign Language Learning Theory and Practice,4,18-23.

[28] Zheng Shutang . (2008). New Horizon College English 2 (Second Edition). Beijing: Foreign Language Teaching and Research Press, 2, 3.

[29] Zimmerman, C. B. (2001). Historical trends in second language vocabulary instruction. In J. Coady, \& T. Huckin (Eds.), Second language vocabulary acquisition (pp.5-19). Shanghai, CHINA: Shanghai Foreign Language Education Press. 
Jun Chen was born in Lianshui, China in 1977. He received his master's degree in English Education from Xuzhou Normal University, China in 2011.

$\mathrm{He}$ is currently a lecturer in the School of Foreign Languages, Huaiyin Institute of Technology, Huaian, China. His research interests include Second Language Acquisition and Foreign Language Teaching. 